\title{
An overview of biomass conversion: Exploring new opportunities
}

\author{
László Fülöp $^{\text {Corresp., } 1}$, János Ecker ${ }^{1}$ \\ 1 Department of Chemistry, Szent István University, Gödöllő, Hungary \\ Corresponding Author: László Fülöp \\ Email address: Dr.Fulop.Laszlo@gmail.com
}

Recycling biomass is indispensable these days not only because fossil energy sources are gradually depleted, but also because pollution of the environment, caused by the increasing use of energy, must be reduced. This paper intends to overview the results of plant biomass processing methods that are currently in use. Our aim was also to review published methods that are not currently in use. It is intended to explore the possibilities of new methods and enzymes to be used in biomass recycling. The results of this overview are perplexing in almost every area. Advances have been made in the pre-treatment of biomass and in the diversity and applications of the enzymes utilized. Based on molecular modeling, very little progress has been made in the modification of existing enzymes for altered function and adaptation for the environmental conditions during the processing of biomass. There are hardly any publications in which molecular modeling techniques are used to improve enzyme function and to adapt enzymes to various environmental conditions. Our view is that using modern computational, biochemical, and biotechnological methods would enable the purposeful design of enzymes that are more efficient and suitable for biomass processing. 


\section{An overview of biomass conversion: Exploring new 2 opportunities}

3

4 László Fülöp ${ }^{1}$, János Ecker ${ }^{2}$

5

$6 \quad{ }^{1}$ Department of Chemistry, Szent István University, Gödöllö, Hungary

$7 \quad 2$ Department of Chemistry, Szent István University, Gödöllő, Hungary

8

9 Corresponding Author:

10 László Fülöp ${ }^{1}$

11 Páter Károly út 1., Gödöllö, 2100, Hungary

12 Email address: dr.fulop.laszlo@gmail.com 


\section{ABSTRACT}

Recycling biomass is indispensable these days not only because fossil energy sources are gradually depleted, but also because pollution of the environment, caused by the increasing use of energy, must be reduced. This paper intends to overview the results of plant biomass processing methods that are currently in use. Our aim was also to review published methods that are not currently in use. It is intended to explore the possibilities of new methods and enzymes to be used in biomass recycling. The results of this overview are perplexing in almost every area. Advances have been made in the pre-treatment of biomass and in the diversity and applications of the enzymes utilized. Based on molecular modeling, very little progress has been made in the modification of existing enzymes for altered function and adaptation for the environmental conditions during the processing of biomass. There are hardly any publications in which molecular modeling techniques are used to improve enzyme function and to adapt enzymes to various environmental conditions. Our view is that using modern computational, biochemical, and biotechnological methods would enable the purposeful design of enzymes that are more efficient and suitable for biomass processing.

\section{INTRODUCTION}

The importance of biomass recycling is that the usage of fossil fuels can be reduced towards the goal of realizing a more sustainable mix of energy sources. Biomass is a renewable energy source, and is reproduced in a short life cycle, usually within one year (Wang et al., 2018). Plant biomass that is recycled annually on Earth is estimated to be about 200 billion $\left(2 \times 10^{11}\right)$ tonnes/year (Bjerre et al., 1996). Most of this is in the form of lignocellulose. The aim of biomass recycling is to extract, process and convert the major carbohydrate components (sucrose, starch, cellulose, hemicellulose) in plant material into valuable chemical components or fuel (Schlaf et al., 2016). With the use of biomass, the use of current energy sources (coal, natural gas, oil) can be reduced. This can result in lower air pollution and slow down the rate of increase in the athmospheric $\mathrm{CO}_{2}$ content (suppressing the greenhouse effect and global warming) (Song et al., 2016). We believe that it is important to explore all opportunities to apply existing physical, chemical, microbiological, biochemical and biotechnological knowledge, and apply the results to improve biomass conversion and utilization processes.

\section{Plant Cell Wall Polysaccharides}

Cellulose is one of the most stable molecules on Earth. The glucose associated with the $\beta-1,4-$ O-glucosidic bonds forms cellulose (Heinze et al., 2018). Within the polymer molecule, H-bonds are formed between the ring's oxygen and the 3-OH group, while H-bond is also formed through the O-glycosidic bond and the 6-OH group between the chains (Shuangxi et al., 2020). This cross-linked structure effectively prevents the enzymatic degradation of the polymer molecule since the O-glycosidic bonds are difficult to access for enzymes (Rosenau et al., 2018). Thus, the hydrolysis of cellulose molecules is difficult to accomplish without help. The breakdown of cellulose is also hampered by the fact that hydrolysis of the O-glycosidic bonds may be reversed due to the immobility of the molecules.

Hemicelluloses are polysaccharides that, in addition to cellulose, are involved in building up the cell wall (Houfani et al., 2020). Their role is to fix the cell wall skeleton and connect it to the cellulose fiber network. The practical distinction between cellulose and hemicellulose is made possible by the fact that cellulose is not soluble in $\mathrm{NaOH}$ solution, while polysaccharides with 
59 lower molecular weight and the different polysaccharides of hemicellulose are soluble (Kojima et

60 al., 2019). On the other hand, acid hydrolysis of hemicelluloses takes place under milder

61 conditions than that of cellulose; with dilute sulfuric acid, almost all of the hemicellulose content

62

63 only be hydrolyzed with concentrated hydrochloric acid or $60-80 \%$ sulfuric acid at more than $100^{\circ} \mathrm{C}$ temperature and under high pressure (Lee \& $\left.Y u, 2020\right)$.

The hemicellulose content of plants is predominantly pentosan, and thus arabinan is formed by L-arabinose associated with 1,2-, 1,3- and 1,5-O-glycosidic bonds. Xylan consists of xylose linked by beta-1,4-O-glycosidic bonds. The chain may be linked to alpha-L-arabinose and alphaD-glucose (Serna-Saldivar \& Hernández, 2020). Xyloglucan and arabino-galactan also contain sugars composed of five and six carbon atoms. Galactomannans are made up of beta-Dmannoses which are connected by beta-1,4-O-glycosidic bonds, formed by a side chain bound by beta-D-galactose with 1,6-O-glycosidic bonds (Rodriguez-Canto et al., 2019).

Pectins, together with hemicelluloses and proteins, form the base matrix of the middle plate and cell walls (Stoffels et al., 2020). Most of the pectin consists of alpha-D-galacturonic acid. The chain is interrupted in part by alpha-L-rhamnose, to which the alpha-L-arabinose chain and the alpha-D-galactose chain may be attached (Shakhmatov, Toukach \& Makarova, 2020).

Lignin is deposited in the molecular size cavities of the cell wall of cellulose and hemicellulose, increasing the mechanical resistance of the cell wall (Setälä et al., 2020). Lignin found in different wood species or in plant parts have different structure, but there are structural similarities: the aromatic rings are often linked by a methoxy group or a phenolic hydroxyl group (Li et al., 2020). Lignin is a constituent of tissues of plants. Three cinnamon alcohol derivatives (sinapyl alcohol, $p$-coumaryl alcohol, coniferyl alcohol) are involved in the construction of lignin. From these, the macromolecular lignin is formed by the action of a dehydrogenase enzyme (Elder et al., 2020). Lignin can interact in several ways with cellulose and hemicellulose.

\section{Review methodology}

The following search terms were used for database search: polysaccharides, cellulose hemicellulose lignin biodegradation, modification, immobilization, industry. O-glucosyl hydrolase, cellulase enzyme modeling, molecular modeling, computation, cellulase modification, cellulose enzyme modification modeling. The search was combined with OR and AND terms. Searches were carried out up until 2020. We have also reviewed the articles and references therein. The articles we found interesting with respect to the problem area highlighted above were classified into the following categories: Biodegradation of polysaccharides; Mechanical and physico-chemical modifications of substrates; Cellulose hemicellulose lignin modification; Modification of enzymes; Immobilization of enzymes; Molecular modeling of enzymes. From these articles, we compiled our study to examine the use of model-based enzyme modifications or rational design in contrast to conventional methods.

\section{BIODEGRADATION OF POLYSACCHARIDES}

The production of ethanol, which can also be used as a fuel, is still almost exclusively fermentation-based. For this, the raw material (sucrose and starch) is obtained from sugar cane, sugar beet, cereals, and potatoes (Arnold et al., 2019). These so-called first-generation biofuel technologies necessarily raise ethical, environmental and political concerns due to the raw materials used in these processes. Therefore, second-generation technologies (Satari et al., 2019) 
105

106

107

108

109

110

111

112

113

114

115

116

117

118

119

120

121

122

123

124

125

126

127

128

129

130

131

132

133

134

135

136

137

138

139

140

141

142

143

144

145

146

147

148

149

150

are under constant development. These technologies can utilize lignocellulose-containing byproducts of agriculture and forestry, as well as industrial wastes or residues along with crops that are not used for food production. Unlike the first-generation methods that process only a relatively small proportion of plants (root, stem, crop), processing the entire biomass is possible with second-generation technologies. The third-generation methods (Mahjoub et al., 2020) are used to process algae and microorganisms into biofuels. Fourth-generation biofuel processes use genetically modified algae to further enhance fuel production.

How can biomass-based fuel production methods be improved for greater efficiency or productivity? One option is modifying processing conditions (temperature, $\mathrm{pH}$, physical and chemistry parameters) or altering the substrate with physical chemistry methods. Another possibility is to look for newer and more specific enzymes to utilize biomass. The third approach is to modify the existing enzymes and increase their efficiency. These options are reviewed below.

\section{Mechanical, physico-chemical and biotechnological modifications of substrates}

Pre-treatment of biomass can be physical, chemical, physico-chemical and biological. The recovered polysaccharides (cellulose, hemicellulose) can be degraded by mild acidic or enzymatic hydrolysis (Cann et al., 2020). Monosaccharides (glucose, mannose, xylose, arabinose, etc.) obtained by hydrolysis of polysaccharides are sources of valuable components (methanol, ethanol, furfural and derivatives, hydroxymethyl-furfural, levulinic acid, succinic acid, lactic acid, sorbitol, etc.) (Van Walsum et al., 1996, Ramli \& Amin, 2020). The purpose of physical pretreatment is to reduce the particle size by grinding. The energy requirements are usually high, so these methods cannot be economical procedures on an industrial scale.

One possible way of chemical pretreatment is the lignin breakdown with ozone, which occurs at room temperature under atmospheric pressure and does not produce toxic byproducts. However, this method is very expensive due to the use of ozone (Figueirêdo, Heeres \& Deuss, 2020). Acid or alkaline hydrolysis is more important in practice (Kobayashi \& Fukuoka, 2013). An example of the former is mild acid pre-treatment with sulfuric acid, which can be carried out in a high-temperature continuous reactor. Hemicelluloses can be released from the plant cell wall with alkali (Tribot et al., 2019). After alkaline extraction, most hemicellulose fractions dissolve in water (Teymouri et al, 2005; Deepa et al., 2011; Kamm, Gruber \& Kamm, 2016). General experience shows that treatment with ionic liquids causes both carbohydrates and lignin to be soluble but not degraded (Ramli \& Amin, 2020). Another possibility for chemical pre-treatment is the use of organic solvents; in this case, an organic solvent is used in the presence of an inorganic acid catalyst to break down the bonds between hemicelluloses and lignin to bring the lignin into solution (Wang C. et al., 2020). The structure of lignin and the linkages between lignin and hemicellulose and cellulose can be broken by acetyl group removal as well, and the successive enzymatic hydrolysis of cellulose can be enhanced (Huang J. et al., 2019).

The impact of various pre-treatment processes on improving the surface morphology of wheat straw has been investigated using polystyrene composite films. The surface was improved by the enhancement of the susceptible cellulose area; therefore, the modified material can be used for various industrial green packaging applications (Dixit \& Yadav, 2019). The effect of alkalibleach treatment has successfully obtained microfibrillated cellulose from stalk sweet sorghum waste fibers (Ismojo et al., 2019). Almost complete biomass saccharification was achieved with $4 \% \mathrm{NaOH}$ at $50{ }^{\circ} \mathrm{C}$. (Alam et al., 2019). A group showed that ball milling can lead to the 
151

152

153

154

155

156

157

158

159

160

161

162

163

164

165

166

167

168

169

170

171

172

173

174

175

176

177

178

179

180

181

182

183

184

185

186

187

188

189

190

191

192

193

194

195

depolymerization of cell-wall polymers, especially the polysaccharides. Micromorphology characterization showed that mechanical manipulation disintegrated fibrillar matrices. The $\beta-1,4$ glycosidic bond breakage in cellulose, along with the decomposition of arabinoxylans suggested the modification in polysaccharide chains (Liu H. et al., 2019). In conclusion, mechanochemical methods can be used to create more digestible plant material.

The addition of naphthol derivatives can enhance the enzymatic hydrolysis, as was described by Lai (Lai et al., 2018; Fei et al., 2020). P-toluenesulfonic acid can remove wood lignin. Disk refining with subsequent acid hydrolysis (so-called physicochemical treatment) doubled the delignification efficiency (Gu et al., 2019).

In a 2-propanol alkaline medium, arabinoxylans were derivatized by carboxymethylation with sodium monochloroacetate. With this method, it is possible to produce hemicellulosic derivatives from corn fibers without using extreme conditions in solvents and temperature (de Mattos et al., 2019). Lignocellulose crops serve as an excellent feedstock for biofuels because of their reduced costs and net carbon emission, and higher energy efficiency. Results showed that Miscanthus sacchariflorus possesses lower lignin and higher polysaccharide content in its leaves and stalks, compared to other Miscanthus species, therefore it is a better bioenergy crop (Jung, Kim \& Chung, 2015). It was found that an alkali treatment leads to gradual removal of binding materials, such as hemicellulose and lignin from bamboo fiber (Zhang, Wang \& Keer, 2015; Chin et al., 2020). The wood waste and cellulose, hemicellulose handled with cyclic anhydrides in a green reactive and solvent-free extrusion will allow targeted modification of composites (Vaidya, Gaugler \& Smith, 2016). Suhas focused on the utilization of cellulose as an adsorbent in natural/modified form or as a precursor for activated carbon (Suhas et al., 2016; Liu et al., 2016). Cellulose, lignin, and hemicellulose were tested to hydrothermal carbonization in different temperature ranges and time. The effects of these parameters were combined and investigated indepth (Borrero-López et al., 2018). Modification of pectin improves its physicochemical properties, thus allowing the availability of other components (Buergy et al., 2020; Wang W. et al., 2020).

Modified microfibrillated cellulose was used with three different coupling agents: 3aminopropyl triethoxysilane, 3-glycidoxypropyltrimethoxysilane, and titanate-containing agent to improve the mechanical properties of the cellulose-based material. The modifications changed the surface character of the cellulose from hydrophilic to hydrophobic (Biliuta \& Coseri, 2019), and an epoxy resin system can be created with better mechanical properties of regular composite materials (Lu et al., 2008). Results showed that banana fiber modified by alkaline treatment is a low-cost alternative for metal removal in aqueous industry effluents (Barreto et al., 2010). Lignin is mostly used as a filler or additive. It may be an excellent candidate for chemical modifications and reactions due to its phenolic and aliphatic hydroxyl groups for the development of new biobased materials (Laurichesse \& Avérous, 2014; Bertella \& Luterbacher, 2020).

Zeng reviewed the recent advances in understanding lignin structure in plant cell walls and the negative roles of lignin in the processes of converting biomass to biofuels (Zeng et al., 2014). Modification of the degree of 4-O-methylation of secondary plant cell wall glucuronoxylan is important for better utilization of plant biomass for biofuel production (Yuan et al., 2014). Huang indicated that to enhance biomethane yield of corn stover, Ceriporiopsis subvermispora modification is one of the most effective methods. Increasing the number of reducing ends in $\beta$ 1,4-glucan chains positively affected biomass enzymatic saccharification. This demonstrates a 
196

197

198

199

200

201

202

203

204

205

206

207

208

209

210

211

212

213

214

215

216

217

218

219

220

221

222

223

224

225

226

227

228

229

230

231

232

233

234

235

236

237

238

239

240

241

potential strategy for genetic modification of cellulose microfibrils in bioenergy crops (Huang W. et al., 2019).

\section{Application of new and special enzymes}

Lignin-degrading enzymes that are produced mainly by fungi, are capable of depolymerization and modification of lignin. The most studied representatives of these enzymes are lignin peroxidase, manganese peroxidase and laccase (Eriksson \& Bermek, 2009; Zhao et al., 2020). Dashtban describes ligninolytic enzyme families that are involved in wood decay processes. The molecular structures, biochemical properties, and the mechanisms of action which make them useful candidates in biotechnological applications, such as pulp bio-bleaching, biosensors, food industries, textile industries, soil bioremediation and in the production of complex polymers in synthetic chemistry are also described (Dashtban et al., 2010). With anaerobic digestion of organic waste high in lignocellulose content, methane was synthesized by using laccase, hemicellulose, and cellulase enzymes (Luo et al., 2010; Abraham et al., 2020).

It was proved that horticultural waste was a potential feedstock for fuel using Saccharomyces cerevisiae ethanol production and a special pre-treatment method was developed (Geng, Xin \& $I p$, 2012). Polysaccharide conversion within the lignocellulosic biomass by enzymes is under intensive research (Horn et al., 2012). Other researchers isolated a special pectate lyase enzyme that had high thermal and $\mathrm{pH}$ stability and was able to produce pectin oligosaccharides from food waste (Wang Z. et al., 2020).

Li investigated the microbial communities involved in anaerobic digestion along with the methane production characteristics of cellulose, hemicellulose, and lignin. The results showed that the biomethane potential of cellulose was higher than that of hemicellulose; however, hemicellulose was hydrolyzed more quickly than cellulose, while lignin was very difficult to be digested ( $\mathrm{Li}$ et al., 2018). Lignocellulosic enzymes, such as cellulases and xylanases were used to modify paper pulp characteristics (Siqueira et al., 2020). The tear strength of recycled paper was found to be increased after enzymatic treatment (Kumar et al., 2018).

When a commercial cellulase mixture was supplemented with xylanases, substrates could be readily hydrolyzed, recovering most of the hemicellulose and cellulose as monomeric sugars (Wu, Chandra \& Saddler, 2019). Ying concluded that lignin could bind to cellulases and decrease the enzyme accessibility to cellulose fibres. Modified lignins were prepared from alkali lignin; the post-treatment weakened the adsorption rate between lignin and cellulase enzymes and improved the enzymatic saccharification efficiency (Ying et al., 2018). Lignin peroxidase (LiPH8) from the white-rot fungus Phanerochaete chrysosporium can efficiently catalyze the degradation of lignin (Majeke et al., 2020). The in silico designed and engineered LiPH8 showed improved stability, as well as a higher activity under acidic $\mathrm{pH}$ conditions (Pham et al., 2018). Several methods have been developed to immobilize cellulase enzymes. The results indicate that cheap supports can be used to effectively immobilize enzymes (Zang et al., 2018).

A research group tried the hydrolysis of hemicellulose and cellulose into fermentable sugars which needs a pre-treatment of the whole material to remove unnecessary components from the biomass (Laca, Laca \& Díaz, 2019). Pentose sugars, which are formed by hydrolyzing hemicelluloses, cannot be fermented with Saccharomyces cerevisiae, therefore, other ethanologenic species, e.g. Zymomonas mobilis are used to break down pentose. Liu critically reviewed the progress in this field and highlighted challenges and strategies for solutions (Liu C. et al., 2019). An integrated process of cellulase production and pre-treatment employing Piptoporus betulinus was proposed to accomplish the economic feasibility of lignocellulosic 
242

243

244

245

246

247

248

249

250

251

252

253

254

255

256

257

258

259

260

261

262

263

264

265

266

267

268

269

270

271

272

273

274

275

276

277

278

279

280

281

282

283

284

285

286

287

ethanol ( $\mathrm{Li}$ et al., 2019). Biofuel produced from lignocellulosic biomass by hydrolysis of fungal consortium enzymes is an environmentally friendly method (Cherukuri et al., 2019).

Wierzbicki summarizes biotechnological approaches to improve industrial processing (Wierzbicki et al., 2019). Structurally different glycosyl hydrolases (enzyme families) were studied. The softwood fiber modification rate by enzymes was studied, dissolved sugar concentrations were measured, and the results were summarized (Rahikainen et al., 2019). To achieve an efficient bioethanol production process, cellulase enzymes are under consideration as potential biocatalysts (Verardi et al., 2020). Shah made an overview of cellulases, specifically covering their utilization and bioconversion from a proteomics, biochemistry, and genetics perspective (Shah, Ranawat \& Mishra, 2019).

\section{Modify the enzymes and increase their efficiency}

\section{Modification and utilization of enzymes by molecular biological, biotechnological, and computational methods}

The substrate specificity and activity of enzymes should be increased to reduce the costs of biofuel production. Various qualities can be improved in enzymes, including specificity, catalytic activity and thermostability, all under industrial conditions (Prajapati et al., 2014).

In the past few years, cellulases have been successfully immobilized with various methods (Mubarak et al., 2014; Mo et al., 2020). Cellulase immobilization onto coffee surface provides an excellent base for increasing the enzyme productivity and different uses of the enzyme (Buntić et al., 2018). Gao developed a rapid method to immobilize cellulases onto graphene oxide. The immobilization was highly efficient and shows great potential for the immobilization of other enzymes (Gao et al., 2018).

Various fungi which break down lignin by their oxidoreductase enzymes (manganese peroxidases, laccases, lignin peroxidases) (Trametes, Polyporus, Pleurotus) can also be used to release cellulose. These enzymes may attack the cellulose and hemicelluloses, so sugar loss can occur during the pre-treatment, and the treatments are very time-consuming (Houfani et al., 2020). Fungal enzymes make up more than half of the enzymes currently used in industrial applications. They play a major role in the modification, partial or complete degradation of polysaccharides into oligomers and monomers (de Vries et al., 2020).

Cellulase adsorption and inactivation in the presence of lignin is the main concern in the case of lignocellulose conversion to biofuels. Relatively little research deals with the necessary protein structure-function relationships. By molecular modeling, highly active, low lignin - binding cellulases can be determined (Haarmeyer et al., 2017).

Understanding enzyme mechanisms at the molecular level is a fundamental requirement in the case of cellulases and ligninases to produce fuel from renewable biomass more efficiently and to utilize plant biomass as a sustainable energy resource. To study the three-dimensional structure of the enzymes and the substrates, along with the enzyme-substrate interactions, computational approaches like molecular dynamics (MD) simulations, ligand-enzyme docking, and quantum chemical calculations are commonly used to give a more detailed description of interaction mechanisms between the enzyme and its substrate (Meng et al., 2011).

For selected fungal cellulases, the acidic quality was determined by in silico physicochemical characterization. One molecular docking study revealed that the amino acid side chains of 
288

289

290

291

292

293

294

295

296

297

298

299

300

301

302

303

304

305

306

307

308

309

310

311

312

313

314

315

316

317

318

319

320

321

322

323

324

325

326

327

328

329

330

331

332

333

cellulases which interact with cellulose may vary, based on the source organism of the enzyme (Tamboli et al., 2017).

The hydrolytic activity of cellulases depends mostly on the binding affinities of the enzyme with cellulose (Krishnaraj et al., 2017). These results were obtained by molecular docking and this method is useful in industrial biotechnology to design more effective enzyme structures (Amore et al., 2017).

The activity of xylanases can be characterized under different conditions. Computational models can help to scale down the experimental costs and save time by identifying enzymes with appropriate activity for scientific and industrial usage (Ariaeenejad et al., 2018).

Hamre made a comparison of three different cellulases by thermodynamic signatures of substrate binding (Hamre et al., 2019).

Based on an in silico study cold-active enzymes have many more advantages compared to mesophilic enzymes. It is concluded that this approach would be valuable for further research and application at the industrial level (Latip, Hamid \& Nordin, 2019).

The study of Mahmood shows an approach by an in silico analysis to identify hot spot amino acid residues responsible for enhancing the thermostability of enzymes of industrial importance (Mahmood et al., 2019).

Ligninolytic enzymes can mediate lignin waste degradation. The most common ligninolytic enzymes are laccase, lignin peroxidase, and manganese peroxidase. In the study of Chen (Chen et al., 2011), lignin binding to these enzymes was determined. The robustness of the binding modes was verified by MD simulations. Residues Ser113, Pro346, Glu460 in laccase, residues Asp183, Arg43, Ala180 in lignin peroxidase and residues Arg177, Arg42, His 173 in manganese peroxidase were the most critical in binding of lignin, respectively. Interaction analyses indicated that hydrophobic interaction plays a crucial function in the designation of substrate specificity. This information can be used as a reference for designing enzymes with better lignin-degrading properties.

Mäkelä described the utilization of wood and dried annual plant biomass using Basidiomycetes, along with the biotechnological potential of the fungal enzymes for the use of plant biomass (Mäkelä et al., 2020).

Gerini (Gerini et al., 2003) investigated the dynamical and structural properties of lignin peroxidase, a heme-containing enzyme with broad substrate specificity, and its Trp171Ala mutant (Blodig et al., 2001) in aqueous solution using MD simulations. The conformational changes in the so-called ligand access channel, which structure was described previously by Poulos, (Poulos et al., 2003) have been analyzed to investigate possible variations of its size, which is very important in determining the substrate accessibility to the enzymatic active site. The analysis of the MD trajectories also showed significant fluctuations of the residues forming the ligand access channel, where the open and closed states are in constant equilibrium in solution. These movements grant the access of the substrate to the enzyme active site. Steered molecular dynamics (SMD) docking simulations have shown that the natural substrate of lignin peroxidase, veratrol, can approach the heme edge through the ligand access channel of the enzyme.

Furthermore, MD simulations made by Ecker and Fülöp (Ecker \& Fülöp, 2018) showed that small-sized ligands can not necessarily enter the channel due to their specific interactions with channel residues.

To determine the energetics and extent of the interactions between various solvents and the cellulosic oligomers, a force field for ionic liquids was developed by Liu (Liu et al., 2010). The 
334 behavior of cellulose was examined using MD simulations of a series of glucose oligomers. The

335

336

337

338

339

340

341

342

343

344

345

346

347

348

349

350

351

352

353

354

355

356

357

358

359

360

361

362

363

364

365

366

367

368

369

370

371

372

373

374

375

376

377

378

379 simulation included cellulose oligomers in two solvents - methanol and water - which can precipitate cellulose from ionic solutions. The results showed that some of the cations were found to be in strong contact through hydrophobic interactions with the polysaccharides, and the interaction energy between the liquid and the polysaccharide chain was stronger than in the case of methanol or water. These results suggest that cationic interactions play a dominant role in the dissolution of cellulose.

In his paper, Kun examined the degradation of plant biomass in a special way, e.g. CRISPR / Cas9 genome editing and adaptive evolution (Kun et all., 2019).

Similarly, Jaeger (Jaeger, Burney \& Pfaendtner, 2015) used MD to investigate the differences in ionic liquid tolerance among three family 5 cellulases from Trichoderma viride, Thermogata maritima, and Pyrococcus horikoshii. Their analysis demonstrates that the effects of ionic liquids on the enzymes vary in each case from local structural disturbances to loss of much of one of the enzyme's secondary structure. Enzymes with more negatively charged surfaces are much more difficult to destabilize by ionic liquids. Ions in aqueous solutions affect the specificity of enzymes.

Wohlert and Berglund (Wohlert \& Berglund, 2011) have built a coarse-grained model of cellulose for MD simulations, using cellobiose from the MARTINI coarse-grained force field (López et al., 2009). The model was extrapolated to longer cellooligomers, and they obtained a model which gives an ordered structure of cellulose in water.

By mutating tryptophans to alanine, Payne (Payne et al., 2011) calculated the relative ligand binding free energy of family 6 cellulases (Cel6A). Their results propose that aromatic residues directly upstream of the active site are not directly implied in binding. However, this is necessary for the glucopyranose ring distortion which plays a role in catalysis. Removal of aromatic residues at the entrance and exit of the enzyme tunnel highly affects the binding affinity. This suggests that these residues play a role in chain acquisition and product stabilization. By MD and normal mode analysis, the roles suggested from differences in binding affinity were confirmed. Aromatic-carbohydrate interactions depend on the residue positions in the enzyme channel. These results have implications for understanding protein structure-function relationships in carbohydrate metabolism and protein engineering strategies for biomass utilization since aromatic-carbohydrate interactions are present in all carbohydrate-active enzymes.

Wakai constructed a genetically modified strain that simultaneously contained cellobiohydrolase, endoglucanase, and $\beta$-glucosidase; multiple copies of the coding genes were integrated. The resulting transformant showed 40-fold higher cellulolytic activity (Wakai et al., 2019).

High temperatures are optimal for thermophile cellulases for cleaving sugars from cellulose as was described by Batista (Batista et al., 2011). In the thermo-resistant cellulase (Ce19A-68), the cellulose-binding domain (CBM) and the catalytic domain are connected by a Pro-Ser-Thr rich linker. There is a cooperative connection between these domains. The mechanism of action of the CBM is still lacking. Higher collective motions were detected at higher temperatures by simulations. Analysis of the motions showed an interdomain where Gly460 and Asp459, located at the linker region, are the hinge residues. Therefore, thermophile cellulases are useful models to study the interactions of the two domains since these collective motions and cooperative connection need higher temperatures to occur at a detectable scale.

To examine the linker function, Payne (Payne et al., 2013) performed MD simulations on Family 6 and 7 cellobiohydrolases bound to cellulose. The presence of glycosylated linkers 
380 bound to cellulose suggests a previously unknown role in enzyme action. By measuring the 381 binding affinity of the Cel7A CBM and the natively glycosylated Cel7A CBM-linker, this 382 prediction was examined experimentally. The glycosylated linker on the crystalline cellulose 383 increases the affinity of CBM binding. The bound linker may affect enzyme action due to 384 significant damping in the enzyme fluctuations, as MD simulations suggest. The glycosylated 385 linkers in carbohydrate-active enzymes aid in dynamic binding during the enzymatic breakdown 386 of plant cell walls.

387

Based on the previous study, Costa (Costa, Silva \& Batista, 2018) identified two residues (Gly460 and Pro461) located at the linker that act as a hinge point and assumed that a Pro461Gly and a Gly460+ (with an extra glycine) constructs of a Cel9A-68 would present enhanced interdomain motions, while the Gly460Pro mutant would be rigid. The Pro461Gly mutation resulted in an extension of the conformational space, as confirmed by clustering and free energy analyses. If the enzyme has more possible conformations, its substrate-binding and degrading potential may also be higher. The engineering seems to be an efficient way to change the enzyme activity and to facilitate the disruption of cellulose fibers.

The product site of cellulase tunnel is inhibited by monosaccharides and disaccharides, so it is a key ingredient of cellulase action on cellulose. The absolute binding free energy of cellobiose and glucose to the product site of the catalytic tunnel of the Family 7 cellobiohydrolase (Cel7A) was calculated by Bu (Bu et al., 2011) using two different approaches: SMD simulations and alchemical free energy perturbation molecular dynamics (FEP/MD) simulations. Analysis of the SMD pulling trajectories suggests that several protein residues play key roles in glucose and cellobiose binding to the catalytic tunnel. Five mutations were made computationally to measure the changes in free energy during the product expulsion process. The results showed that new enzymes can make the conversion of biomass more efficiently.

In wood-fed animals, lignocellulose-rich biomass is utilized appropriately by symbiotic microorganisms. Lignocellulose-based biotechnological processes work in a similar way (Ozbayram, Kleinsteuber \& Nikolausz et al., 2020).

Textor (Textor et al., 2013) reported the first crystal structure of the catalytic core domain of Cel7A (cellobiohydrolase I) from Trichoderma harzianum IOC 3844. The flexibility of Tyr side chains in the active center is increased compared to the reference Trichoderma reesei Cel7A due to slightly shorter side chains of adjacent amino acids. This creates an additional gap at the side face of the catalytic tunnel. T. harzianum cellobiohydrolase I interacts with the substrate of T. reesei Cel7A.

Silveira and Skaf (Silveira \& Skaf, 2015) used MD simulations to collect data about the binding of cellobiose to Trichoderma reesei Cel7A (TrCel7A) cellobiohydrolase and the effects of mutations that may reduce cellobiose binding, without affecting the integrities of the enzyme. The product binding site shows inside flexibility, that can sterically prevent cellobiose release. The enzyme-substrate interactions can be reduced by point mutations, and not necessarily preserve the structure of the enzyme. Mutation of charged residues in the TrCel7A product binding site causes perturbations that affect the structure of the substrate-binding tunnel and may affect TrCel7A function in other steps of the hydrolysis mechanism. The results show there is a connection between product inhibition and catalytic performance, and these may designate directions for cellulase engineering.

\section{Modification of enzymes using molecular modeling methods}


426

427

428

429

430

431

432

433

434

435

436

437

438

439

440

441

442

443

444

445

446

447

448

449

450

451

452

453

454

455

456

457

458

459

460

461

462

463

464

465

466

467

468

469

470

471

There are several ways to improve the enzymes currently used for biomass processing. Molecular modeling techniques can be used to modify enzymes to function more efficiently under the given physicochemical conditions.

By studying the function of the enzymes and catalytic conditions, it is possible to intervene in the chemical reactions by modifying the enzyme structure to better suit the actual processing. To do this, we need to know the enzymatic processes used and modify the function of enzymes by computer modeling and design, in the hope of better utilization.

Nonspecific adsorption of cellulases to lignin prevents enzymatic biomass conversion. Computations show that cellulase with a negatively supercharged surface could reduce lignin inhibition. It is possible to construct highly active cellulases that are resistant to lignin-mediated inactivation, although further work is needed to understand this problem (Whitehead et al., 2017).

Enzymes that break down polysaccharides are often linked with glycosylation, N- and Olinked glycans, the roles of which are only partially understood. Glycans may affect the critical properties of enzymes: N-glycosylation improves thermal and proteolytic stability, Oglycosylation improves CBM-binding affinity and stability along with proteolytic stability, but their presence not necessarily affect catalytic activity (Amore et al., 2017). Modeling of glycosylated cellulases can improve our knowledge about the various functions of the glycans.

Chung described a glycosylated cellulase where mainly galactose disaccharides could be found. This glycosylation dramatically impacted the hydrolysis of insoluble substrates, proteolytic and thermal stability and was found to be necessary for this enzyme to function in harsh environments including industrial settings (Chung et al., 2019).

It is of note that immobilized cellulase-polymethacrylate particles exhibit excellent $\mathrm{pH}$ adaptability compared to free cellulase (Chan et al., 2019).

\section{CONCLUSIONS}

We have explored the possibilities of plant structural biomass utilization along with methods recently studied and applied. Progress has been made in all areas and this field is in constant evolution. New physical and chemical methods have been developed for the pre-treatment of biomass, which can result in extracting biomass materials more efficiently. A wide variety of enzymes in microorganisms have been isolated and used in biomass processing. The mechanism of enzyme function has been studied and new and modified methods have been developed. In our view, there are a few areas that have been seen less development recently. These include changing the properties of existing enzymes using rational design based on structure modeling, MD simulations, enzyme substrate interactions, and virtual mutagenesis.

There are untapped and enormous opportunities to produce modified enzymes that work more effectively under the usually harsh industrial conditions used for biomass processing. Using rational modification of enzymes, the development of biomass conversion, enzyme or process effectiveness can be increased significantly. Physical, chemical, biochemical, biotechnological and molecular biological methods are available to modify the protein side chains in enzymes to provide more efficient biomass utilization that are more appropriate to the techniques employed.

With the widespread application of these methods, further progress is expected in this field, and it can only be supported that in silico modeling, virtual modification of molecules, molecular simulations are used to explore enzyme action under various environmental and/or industrial conditions. This would help to develop the industrial biomass utilization methods used so far

Peer) reviewing PDF | (2020:02:46036:1:0:NEW 4 Jun 2020) 
472 without having to change the method, but only to modify the specific enzymes to work more 473 efficiently under the given conditions, thus increasing productivity and reducing costs.

474

475

476

477

478

479

480

481

482

483

484

485

486

487

488

489

490

491

492

493

494

495

496

497

498

499

500

501

502

503

504

505

506

507

508

509

510

511

512

513

514

515

516

517

\section{Acknowledgements}

The authors thank Dr. Tamás Ponyi and Csaba Biegl PhD for their helpful linguistic and professional comments.

\section{REFERENCES}

Abraham A, Mathew AK, Park H, Choi O, Sindhu R, Parameswaran B, Pandey A, Park JH, Sang BI. 2020. Pretreatment strategies for enhanced biogas production from lignocellulosic biomass.

Bioresource Technology 301:122725 DOI: doi.org/10.1016/j.biortech.2019.122725

Alam A, Zhang R, Liu P, Huang J, Wang Y, Hu Z, Madadi M, Sun D, Hu R, Ragauskas AJ, Tu Y, Peng L. 2019. A finalized determinant for complete lignocellulose enzymatic saccharification potential to maximize bioethanol production in bioenergy Miscanthus.

Biotechnolgy for Biofuels 12:99 DOI: doi.org/10.1186/s13068-019-1437-4

Amore A, Knott BC, Supekar NT, Shajahan A, Azadi P, Zhao P, Wells L, Linger JG, Hobdey SE, Wall TAV, Shollenberger T, Yarbrough JM, Tan Z, Crowley MF, Himmel ME, Decker SR, Beckham GT, Taylor LE. 2017. Distinct roles of N- and O-glycans in cellulase activity and stability. 2017. Proceedings of the National Academy of Sciences of the United States of America 114:13667-13672 DOI: doi.org/10.1073/pnas.1714249114

Ariaeenejad S, Mousivand M, Moradi Dezfouli P, Hashemi M, Kavousi K, Hosseini Salekdeh G. 2018. A computational method for prediction of xylanase enzymes activity in strains of Bacillus subtilis based on pseudo amino acid composition features. Plos One 13:e0205796 DOI: doi.org/10.1371/journal.pone.0205796

Arnold M, Tainter JA, Strumsky D. 2019. Productivity of innovation in biofuel technologies. Energy Policy 124:54-62 DOI: doi.org/10.1016/j.enpol.2018.09.005

Aziz MA, Kassim KA, Bakar WAWA, Marto A, Muhammad SAFS. 2019. Fossil free fuels: Trends in renewable energy. Florida: CRC Press.

Barreto ACH, Costa MM, Sombra ASB, Rosa DS, Nascimento RF, Mazzetto SE, Fechine PBA. 2010. Chemically Modified Banana Fiber: Structure, Dielectrical Properties and Biodegradability. Journal of Polymers and the Environment 18:523-531 DOI: doi.org/10.1007/s10924-010-0216-X

Batista PR, de Souza Costa MG, Pascutti PG, Bisch PM, de Souza W. 2011. High temperatures enhance cooperative motions between CBM and catalytic domains of a thermostable cellulase: mechanism insights from essential dynamics. Physical Chemistry Chemical Physics 13:1370913720 DOI: doi.org/10.1039/C0CP02697B

Bertella S, Luterbacher JS. 2020. Lignin functionalization for the production of novel materials. Trends in Chemistry 2:440-453. DOI: doi.org/10.1016/j.trechm.2020.03.001

Biliuta G, Coseri S. 2019. Cellulose: A ubiquitous platform for ecofriendly metal nanoparticles preparation. Coordination Chemistry Reviews 383:155-173 DOI:

doi.org/10.1016/j.ccr.2019.01.007

Bjerre AB, Olesen AB, Fernqvist T, Plöger A, Schmidt AS. 1996. Pretreatment of wheat straw using combined wet oxidation and alkaline hydrolysis resulting in convertible cellulose and hemicellulose. Biotechnology and Bioengineering 49:568-577 DOI: $\underline{\text { doi.org/10.1002 }}$

Blodig W, Smith AT, Doyle WA, Piontek K. 2001. Crystal structures of pristine and oxidatively processed lignin peroxidase expressed in Escherichia coli and of the W171F variant that 
518

519

520

521

522

523

524

525

526

527

528

529

530

531

532

533

534

535

536

537

538

539

540

541

542

543

544

545

546

547

548

549

550

551

552

553

554

555

556

557

558

559

560

561

562 eliminates the redox active tryptophan 171. Implications for the reaction mechanism. Journal of Molecular Biology 305:851-861 DOI: doi.org/10.1006/jmbi.2000.4346

Borrero-López AM, Masson E, Celzard A, Fierro V. 2018. Modelling the reactions of cellulose, hemicellulose and lignin submitted to hydrothermal treatment. Industrial Crops and Products 124:919-930 DOI: doi.org/10.1016/j.indcrop.2018.08.045

Bu L, Beckham GT, Shirts MR, Nimlos MR, Adney WS, Himmel ME, Crowley MF. 2011. Probing carbohydrate product expulsion from a processive cellulase with multiple absolute binding free energy methods. Journal of Biological Chemistry 286:18161-18169 DOI: doi.org/10.1074/jbc.M110.212076

Buergy A, Rolland-Sabaté A, Leca A, Renard CMGC. 2020. Pectin modifications in raw fruits alter texture of plant cell dispersions. Food Hydrocolloids 107:105962 DOI: doi.org/10.1016/j.foodhyd.2020.105962

Buntić A, Pavlović M, Antonović D, Pavlović V, Vrućinić D, Šiler-Marinković S, DimitrijevićBranković S. 2018. Customizing the spent coffee for Trichoderma reesei cellulase immobilization by modification with activating agents. International Journal of Biological Macromolecules 107 Part B:1856-1863 DOI: doi.org/10.1016/j.ijbiomac.2017.10.060 Cann I, Pereira GV, Abdel-Hamid AM, Kim H, Wefers D, Kayang BB, Kanai T, Sato T, Bernardi RC, Atomi H, Mackie RI. 2020. Thermophilic degradation of hemicellulose, a critical feedstock in the production of bioenergy and other value-added products. Applied and Environmental Microbiology 86:e02296-19 DOI: doi.org/10.1128/AEM.02296-19

Chan Y, Acquah C, Obeng EM, Dullah EC, Jeevanandam J, Ongkudon CM. 2019. Parametric study of immobilized cellulase-polymethacrylate particle for the hydrolysis of carboxymethyl cellulose. Biochimie 157:204-212 DOI: doi.org/10.1016/j.biochi.2018.11.019

Chen M, Zeng G, Tan Z, Jiang M, Li H, Liu L, Zhu Y, Yu Z, Wei Z, Liu Y, Xie, G. 2011. Understanding lignin-degrading reactions of ligninolytic enzymes: Binding affinity and interactional profile. Plos One 6:e25647 DOI: doi.org/10.1371/journal.pone.0025647 Cherukuri P.J., Akkina R.C. (2019). Bioconversion of Biomass to Biofuel Using Fungal Consortium. In: Yadav A., Singh S., Mishra S., Gupta A. (eds) Recent Advancement in White Biotechnology Through Fungi. Fungal Biology pp 381-396. Springer, Cham. DOI: doi.org/10.1007/978-3-030-25506-0_15

Chin SC, Tee KF, Tong FS, Ong HR, Gimbun J. 2020. Thermal and mechanical properties of bamboo fiber reinforced composites. Materials Today Communications 23:100876 DOI: doi.org/10.1016/j.mtcomm.2019.100876

Chung D, Sarai NS, Knott BC, Hengge N, Russell JF, Yarbrough JM, Brunecky R, Young J, Supekar N, Wall TV, Sammond DW, Crowley MF, Szymanski CM, Wells L, Azadi P, Westpheling J, Himmel ME, Bomble YJ. 2019. Glycosylation is vital for industrial performance of hyperactive cellulases. ACS Sustainable Chemistry and Engineering 7:47924800 DOI: doi.org/10.1021/acssuschemeng.8b05049

Costa MGS, Silva YF, Batista PR. 2018. Computational engineering of cellulase Ce19A-68 functional motions through mutations in its linker region. Physical Chemistry Chemical Physics 20:7643-7652 DOI: doi.org/10.1039/C7CP07073J

Dashtban M, Schraft H, Syed TA, Qin W. 2010. Fungal biodegradation and enzymatic modification of lignin. International Journal of Biochemistry and Molecular Biology 1:36-50 Deepa B, Abraham E, Cherian BM, Bismarck A, Blaker JJ, Pothan LA, Leao AL, de Souza SF, Kottaisamy M. 2011. Structure, morphology and thermal characteristics of banana nano fibers

Peer] reviewing PDF | (2020:02:46036:1:0:NEW 4 Jun 2020) 
563

564

565

566

567

568

569

570

571

572

573

574

575

576

577

578

579

580

581

582

583

584

585

586

587

588

589

590

591

592

593

594

595

596

597

598

599

600

601

602

603

604

605

606

607 obtained by steam explosion. Bioresource Technology 102:1988-1997 DOI:

doi.org/10.1016/j.biortech.2010.09.030

de Mattos NR, Colodette JL, de Oliveira CR. 2019. Alkaline extraction and carboxymethylation of xylans from corn fiber. Cellulose 26:2177-2189 DOI: doi.org/10.1007/s10570-018-02236-5 del Río JC, Rencoret J, Gutiérrez A, Elder T, Kim H, Ralph J. 2020. Lignin monomers from beyond the canonical monolignol biosynthetic pathway: Another brick in the wall. $A C S$ Sustainable Chemistry and Engineering 8:4997-5012 DOI:

doi.org/10.1021/acssuschemeng.0c01109

Dixit S, Yadav VL. 2019. Comparative study of polystyrene/chemically modifed wheat straw composite for green packaging application. Polymer Bulletin 77:1307-1326 DOI: doi.org/10.1007/s00289-019-02804-0

Ecker J, Fülöp L. Lignin peroxidase ligand access channel dysfunction in the presence of atrazine. 2018. Scientific Reports 8:5989 DOI: doi.org/10.1038/s41598-018-24478-w

Elder T., Gutiérrez SA., Kim H., Ralph J., Rencoret J., Río Andrade JC. (2020). Lignin Monomers from beyond the Canonical Monolignol Biosynthetic Pathway: Another Brick in the Wall. ACS Sustainable Chemistry and Engineering 8(3):4997-5012. DOI:

doi.org/10.1021/acssuschemeng.0c01109

Eriksson KEL, Bermek H. 2009. Lignin, Lignocellulose, Ligninase. In: Schaechter M, ed. Encyclopedia of Microbiology (Third Edition). Cambridge MA: Academic Press, 373-384.

Fei X, Jia W, Wang J, Chen T, Ling Y. 2020. Study on enzymatic hydrolysis efficiency and physicochemical properties of cellulose and lignocellulose after pretreatment with electron beam irradiation. International Journal of Biological Macromolecules 145:733-739 DOI: doi.org/10.1016/j.ijbiomac.2019.12.232

Figueirêdo MB, Heeres HJ, Deuss PJ. 2020. Ozone mediated depolymerization and solvolysis of technical lignins under ambient conditions in ethanol. Sustainable Energy \& Fuels 4:265-276

DOI: doi.org/10.1039/C9SE00740G

Gao J, Lu C, Wang Y, Wang S, Shen J, Zhang J, Zhang Y. 2018. Rapid immobilization of cellulase onto graphene oxide with a hydrophobic spacer. Catalysts 8:180 DOI:

doi.org/10.3390/catal 8050180

Geng A, Xin F, Ip J. 2012. Ethanol production from horticultural waste treated by a modified organosolv method. Bioresource Technology 104:715-721 DOI: doi.org/10.1016/j.biortech.2011.10.076

Gerini MF, Roccatano D, Baciocchi E, Di Nola A. 2003. Molecular dynamics simulations of lignin peroxidase in solution. Biophysical Journal 84:3883-3893 DOI: doi.org/10.1016/S0006$\underline{3495(03) 75116-9}$

Gu Y, Bian H, Wei L, Wang R. 2019. Enhancement of hydrotropic fractionation of poplar wood using autohydrolysis and disk refining pretreatment: Morphology and overall chemical characterization. Polymers 11:685 DOI: doi.org/10.3390/polym11040685

Haarmeyer CN, Smith MD, Chundawat SPS, Sammond D, Whitehead TA. 2017. Insights into cellulase-lignin non-specific binding revealed by computational redesign of the surface of green fluorescent protein. Biotechnology and Bioengineering 114:740-750 DOI: doi.org/10.1002/bit.26201

Hamre AG, Kaupang A, Payne CM, Väljamäe P, Sørlie M. 2019. Thermodynamic signatures of substrate binding for three Thermobifida fusca cellulases with different modes of action.

Biochemistry 58:1648-1659 DOI: doi.org/10.1021/acs.biochem.9b00014 
608 Heinze T, Seoud OAE, Koschella A. 2018. Cellulose derivatives: Synthesis, structure, and 609 properties. New York City: Springer.

610 Horn SJ, Vaaje-Kolstad G, Westereng B, Eijsink VGH. 2012. Novel enzymes for the degradation

611 of cellulose. Biotechnology for Biofuels 5:45 DOI: doi.org/10.1186/1754-6834-5-45

612 Houfani AA, Anders N, Spiess AC, Baldrian P, Benallaoua S. 2020. Insights from enzymatic

613 degradation of cellulose and hemicellulose to fermentable sugars- a review. Biomass and

614 Bioenergy 134:105481 DOI: doi.org/10.1016/j.biombioe.2020.105481

615 Huang J, Xia T, Li G, Li X, Li Y, Wang Y, Wang Y, Chen Y, Xie G, Bai FW, Peng L, Wang L.

616 2019. Overproduction of native endo- $\beta$-1,4-glucanases leads to largely enhanced biomass

617 saccharification and bioethanol production by specific modification of cellulose features in

618 transgenic rice. Biotechnology for Biofuels 12:11 DOI: doi.org/10.1186/s13068-018-1351-1

619 Huang W, Wachemo AC, Yuan H, Li X. 2019. Modification of corn stover for improving

620

621

622

623

624

625

626

627

628 biodegradability and anaerobic digestion performance by Ceriporiopsis subvermispora.

Bioresource Technology 283:76-85 DOI: doi.org/10.1016/j.biortech.2019.02.035

Ismojo, Novovic A, Lazwardi DR, Zulfia A, Chalid M. 2019. Microfibrillated cellulose (MFC) isolation based on stalk sweet sorghum through alkalinization-bleaching treatment: effect of soaking temperature. IOP Conference Series: Materials Science and Engineering 509:012079 DOI: $\underline{\text { doi.org/10.1088/1757-899X/509/1/012079 }}$

Jaeger V, Burney P, Pfaendtner J. Comparison of three ionic liquid-tolerant cellulases by molecular dynamics. 2015. Biophysical Journal 108:880-892 DOI:

doi.org/10.1016/j.bpj.2014.12.043

629

630

631

632

633

634

635

636

637

Jung S, Kim S, Chung I. 2015. Comparison of lignin, cellulose, and hemicellulose contents for biofuels utilization among 4 types of lignocellulosic crops. Biomass and Bioenergy 83:322-327

DOI: doi.org/10.1016/j.biombioe.2015.10.007

Kamm B, Gruber PR, Kamm M. 2016. Biorefineries-industrial processes and products. Hoboken, NJ: Wiley.

Kobayashi H, Fukuoka A. 2013. Synthesis and utilisation of sugar compounds derived from lignocellulosic biomass. Green Chemistry 15:1740-1763 DOI: doi.org/10.1039/C3GC00060E

Kojima Y, Takayasu M, Toma M, Koda S. 2019. Degradation of cellulose in $\mathrm{NaOH}$ and $\mathrm{NaOH} /$ urea aqueous solutions by ultrasonic irradiation. Ultrasonics Sonochemistry 51:419-423

638 DOI: doi.org/10.1016/j.ultsonch.2018.07.030

639

640

641

642

643

644

645

646

647

648

649

650

Krishnaraj RN, Samanta D, Kumar A, Sani R. 2017. Bioprospecting of thermostable cellulolytic enzymes through modeling and virtual screening method. Canadian Journal of Biotechnology 1:19-25 DOI: doi.org/10.24870/cjb.2017-000105

Kumar NV, Rani ME, Gunaseeli R, Kannan ND. 2018. Paper pulp modification and deinking efficiency of cellulase-xylanase complex from Escherichia coli SD5. International Journal of Biological Macromolecules 111:289-29 DOI: doi.org/10.1016/j.ijbiomac.2017.12.126

Kun RS., Gomes ACS., Hildén KS., Cerezo SS., Mäkelä MR., de Vries RP. (2019).

Developments and opportunities in fungal strain engineering for the production of novel enzymes and enzyme cocktails for plant biomass degradation. Biotechnology Advances 37(6):107361. DOI: doi.org/10.1016/j.biotechadv.2019.02.017

Laca A, Laca A, Díaz M. 2019. Chapter 8 - Hydrolysis: From cellulose and hemicellulose to simple sugars. In: Basile A, Dalena F, ed. Second and Third Generation of Feedstocks.

651 Amsterdam: Elsevier, 213-240. 
652 Lai C, Yang B, He J, Huang C, Li X, Song X, Yong Q. 2018. Enhanced enzymatic digestibility

653 of mixed wood sawdust by lignin modification with naphthol derivatives during dilute acid

654

655 pretreatment. Bioresource Technology 269:18-24 DOI: doi.org/10.1016/j.biortech.2018.08.086 Latip MAA, Hamid AAA, Nordin NFH. 2019. Microbial hydrolytic enzymes: In silico studies

656 between polar and tropical regions. Polar Science 20:9-18 DOI:

657 doi.org/10.1016/j.polar.2019.04.003

658

659

Laurichesse S, Avérous L. 2014. Chemical modification of lignins: Towards biobased polymers. Progress in Polymer Science 39:1266-1290 DOI: doi.org/10.1016/j.progpolymsci.2013.11.004

660

661

Lee I, Yu J. 2020. The production of fermentable sugar and bioethanol from acacia wood by optimizing dilute sulfuric acid pretreatment and post treatment. Fuel 275:117943 DOI:

662 doi.org/10.1016/i.fuel.2020.117943

663

664

665

666

667

Li G, Zhang H, Lu Y, Xue H. 2019. Solid state fermentation process coupled biological pretreatment with cellulase production by Piptoporus betulinus for enhanced cellulose hydrolysis. Cellulose 26:3815-3824 DOI: doi.org/10.1007/s10570-019-02359-3

Li T, Ma H, Wu S, Yin Y. 2020. Effect of highly selective oxypropylation of phenolic hydroxyl groups on subsequent lignin pyrolysis: Toward the lignin valorization. Energy Conversion and

668

669

670 Management 207:112551 DOI: doi.org/10.1016/j.enconman.2020.112551

Li W, Khalid H, Zhu Z, Zhang R, Liu G, Chen C, Thorin E. 2018. Methane production through anaerobic digestion: Participation and digestion characteristics of cellulose, hemicellulose and lignin. Applied Energy 226:1219-1228 DOI: doi.org/10.1016/j.apenergy.2018.05.055

671

672

Liu C, Xiao Y, Xia X, Zhao X, Peng L, Srinophakun P, Bai F. 2019. Cellulosic ethanol

673

674

675

676

677 production: Progress, challenges and strategies for solutions. Biotechnology Advances 37:491504 DOI: doi.org/10.1016/j.biotechadv.2019.03.002

Liu H, Chen X, Ji G, Yu H, Gao C, Han L, Xiao W. 2019. Mechanochemical deconstruction of lignocellulosic cell wall polymers with ball-milling. Bioresource Technology 286:121364 DOI: doi.org/10.1016/j.biortech.2019.121364

678

679

680

Liu H, Sale KL, Holmes BM, Simmons BA, Singh S. 2010. Understanding the interactions of cellulose with ionic liquids: A molecular dynamics study. The Journal of Physical Chemistry B 114:4293-4301 DOI: doi.org/10.1021/jp9117437

681

Liu J, Chen T, Yang YL, Bai Z, Xia L, Wang M, Lv X, Li L. 2020. Removal of heavy metal ions and anionic dyes from aqueous solutions using amide-functionalized cellulose-based

683

684

685 adsorbents. Carbohydrate Polymers 230:115619 DOI: doi.org/10.1016/j.carbpol.2019.115619

López CA, Rzepiela AJ, De Vries AH, Dijkhuizen L, Hünenberger PH, Marrink SJ. 2009. Martini coarse-grained force field: extension to carbohydrates. Journal of Chemical Theory and Computation 5:3195-3210 DOI: doi.org/10.1021/ct900313w

Lu J, Askeland P, Drzal LT. 2008. Surface modification of microfibrillated cellulose for epoxy composite applications. Polymer 49:1285-1298 DOI: doi.org/10.1016/i.polymer.2008.01.028

Luo G, Xie L, Zou Z, Wang W, Zhou Q. 2010. Evaluation of pretreatment methods on mixed inoculum for both batch and continuous thermophilic biohydrogen production from cassava

691

692

693

694

695

696

697 stillage. Bioresource Technology 101:959-964 DOI: doi.org/10.1016/j.biortech.2009.08.090 Mahjoub N, Sahebi H, Mazdeh M, Teymouri A. 2020. Optimal design of the second and third generation biofuel supply network by a multi-objective model. Journal of Cleaner Production 256:120355 DOI: doi.org/10.1016/j.jclepro.2020.120355

Mahmood MS, Rasul F, Saleem M, Afroz A, Malik MF, Ashraf NM, Rashid U, Naz S, Zeeshan N. 2019. Characterization of recombinant endo-1,4- $\beta$-xylanase of Bacillus halodurans $C-125$ and rational identification of hot spot amino acid residues responsible for enhancing 
698

699

700

701

702

703

704

705

706

707

708

709

710

711

712

713

714

715

716

717

718

719

720

721

722

723

724

725

726

727

728

729

730

731

732

733

734

735

736

737

738

739

740

741

742

743 thermostability by an in-silico approach. Molecular Biology Reports 46:3651-3662 DOI: doi.org/10.1007/s11033-019-04751-5

Majeke BM, García-Aparicio M, Biko OD, Viljoen-Bloom M, van Zyl WH, Görgens JF. 2020. Synergistic codon optimization and bioreactor cultivation towards enhanced secretion of fungal lignin peroxidase in Pichia pastoris: enzymatic valorization of technical (industrial) lignins. Enzyme and Microbial Technology 139:109593 DOI: doi.org/10.1016/j.enzmictec.2020.109593 Mäkelä M.R., Hildén K., Kowalczyk J.E., Hatakka A. (2020) Progress and Research Needs of Plant Biomass Degradation by Basidiomycete Fungi. In: Nevalainen H. (eds) Grand Challenges in Fungal Biotechnology. Grand Challenges in Biology and Biotechnology pp 405-438.

Springer, Cham. DOI: doi.org/10.1007/978-3-030-29541-7_15

Meng XY, Zhang HX, Mezei M, Cui M. 2011. Molecular docking: A powerful approach for structure-based drug discovery. Current Computer-Aided Drug Design 7:146-157 DOI: doi.org/10.2174/157340911795677602

Mo H, Qiu J, Yang C, Zang L, Sakai E, Chen J. 2020. Porous biochar/chitosan composites for high performance cellulase immobilization by lutaraldehyde. Enzyme and Microbial Technology 138:109561 DOI: doi.org/10.1016/j.enzmictec.2020.109561

Mubarak NM, Wong JR, Tan KW, Sahu JN, Abdullah EC, Jayakumar NS, Ganesan P. 2014. Immobilization of cellulase enzyme on functionalized multiwall carbon nanotubes. Journal of Molecular Catalysis B: Enzymatic 107:124-131 DOI: doi.org/10.1016/j.molcatb.2014.06.002

Nie S, Hao N, Zhang K, Xing C, Wang S. 2020. Cellulose nanofibrils-based thermally conductive composites for flexible electronics: A mini review. Cellulose 27:4173-4187 DOI: doi.org/10.1007/s10570-020-03103-y

Ozbayram, E.G., Kleinsteuber, S. \& Nikolausz, M. (2020). Biotechnological utilization of animal gut microbiota for valorization of lignocellulosic biomass. Applied Microbiology and Biotechnology 104, 489-508. DOI: doi.org/10.1007/s00253-019-10239-w

Payne CM, Bomble YJ, Taylor CB, McCabe C, Himmel ME, Crowley MF, Beckham GT. 2011. Multiple functions of aromatic-carbohydrate interactions in a processive cellulase examined with molecular simulation. Journal of Biological Chemistry 286:41028-41035 DOI: doi.org/10.1074/jbc.M111.297713

Payne CM, Resch MG, Chen L, Crowley MF, Himmel ME, Taylor LE, Sandgren M, Ståhlberg J, Stals I, Tan Z, Beckham GT. 2013. Glycosylated linkers in multimodular lignocellulosedegrading enzymes dynamically bind to cellulose. Proceedings of the National Academy of Sciences of the United States of America 110:14646-14651 DOI: doi.org/10.1073/pnas.1309106110

Pham LTM, Seo H, Kim K, Kim YH. 2018. In silico-designed lignin peroxidase from Phanerochaete chrysosporium shows enhanced acid stability for depolymerization of lignin. Biotechnology for Biofuels 11:325 DOI: doi.org/10.1186/s13068-018-1324-4

Poulos TL, Edwards SL, Wariishi H, Gold MH. 1993. Crystallographic refinement of lignin peroxidase at 2 A. Journal of Biological Chemistry 268:4429-4440

Prajapati AS, Panchal KJ, Pawar VA, Noronha MJ, Patel DH, Subramanian RB. 2017. Review on cellulase and xylanase engineering for biofuel production. Industrial Biotechnology 14:3844 DOI: doi.org/10.1089/ind.2017.0027

Rahikainen J, Ceccherini S, Molinier M, Holopainen-Mantila U, Reza M, Väisänen S, Puranen T, Kruus K, Vuorinen T, Maloney T, Suurnäkki A, Grönqvist S. 2019. Effect of cellulase family and structure on modification of wood fibres at high consistency. Cellulose 26:50855103 DOI: doi.org/10.1007/s10570-019-02424-X

PeerJ reviewing PDF | (2020:02:46036:1:0:NEW 4 Jun 2020) 
744 Ramli NAS, Amin NAS. 2020. Catalytic conversion of carbohydrate biomass in ionic liquids to 745 5-hydroxymethyl furfural and levulinic acid: a review. BioEnergy Research Published online

74611 April 2020. DOI: doi.org/10.1007/s12155-020-10125-8

747 Rodriguez-Canto W, Chel-Guerrero L, Fernandez VVA, Aguilar-Vega M. 2019. Delonix regia

748 galactomannan hydrolysates: Rheological behavior and physicochemical characterization.

749 Carbohydrate Polymers 206:573-582 DOI: doi.org/10.1016/j.carbpol.2018.11.028

750 Rosenau T, Potthast A, Hell J. 2018. Cellulose science and technology: Chemistry, analysis, and 751 applications. Hoboken, NJ: Wiley.

752 Satari B, Karimi K, Kumar R. 2019. Cellulose solvent-based pretreatment for enhanced second-

753

754

755

756

757

758

759

760

761

762

763

764

765

766

767

768

769

770

771

772

773

774

775

776

777

778

779

780

781

782

783

784

785

786

787

788

789 generation biofuel production: a review. Sustainable Energy \& Fuels 3:11-62 DOI: doi.org/10.1039/C8SE00287H

Schlaf M, Zhang ZC. 2016. Reaction pathways and mechanisms in thermocatalytic biomass conversion I: Cellulose structure, depolymerization and conversion by heterogeneous catalysts. Springer Singapore.

Serna-Saldívar SO, Hernández DS. 2020. Dietary fiber in cereals, legumes, pseudocereals and other seeds. In: Welti-Chanes J., Serna-Saldívar S, Campanella O, Tejada-Ortigoza V, eds. Science and technology of fibers in food systems. Cham: Springer, 87-122.

Setälä H, Alakomi HL, Paananen A, Szilvay GR, Kellock M, Lievonen M, Liljeström V, Hult EL, Lintinen K, Österberg M, Kostiainen M. 2020. Lignin nanoparticles modified with tall oil fatty acid for cellulose functionalization. Cellulose 27:273-284 DOI: doi.org/10.1007/s10570$\underline{019-02771-9}$

Shah F, Ranawat B, Mishra S. 2019. Chapter 11 - An approach toward cellulase production, bioconversion, and utilization. In: Hosseini M, ed. Bioprocessing for alternative fuels, biobased chemicals, and bioproducts. Sawston, Cambridge: Woodhead Publishing, 207-223.

Shakhmatov EG, Toukach PV, Makarova EN. 2020. Structural studies of the pectic polysaccharide from fruits of Punica granatum. Carbohydrate Polymers 235:115978 DOI: doi.org/10.1016/j.carbpol.2020.115978

Silveira RL, Skaf MS. 2015. Molecular dynamics simulations of Family 7 cellobiohydrolase mutants aimed at reducing product inhibition. The Journal of Physical Chemistry B 119:92959303 DOI: doi.org/10.1021/jp509911m

Shuangxi N., Ningke H., Kun Z., Chuyue X., Shuangfei W. (2020) . Cellulose Nanofibers and Other Biopolymers for Biomedical Applications: A Review. Cellulose 27: 4173-4187 DOI: doi.org/10.1007/s10570-020-03103-y

Siqueira JGW, Rodrigues C, Vandenberghe L, Woiciechowski AL, Soccol CR. 2020. Current advances in on-site cellulase production and application on lignocellulosic biomass conversion to biofuels: a review. Biomass and Bioenergy 132:105419 DOI:

doi.org/10.1016/i.biombioe.2019.105419

Song J, Wang Y, Tang J. 2016. A hiatus of the greenhouse effect. Scientific Reports 6:33315 DOI: doi.org/10.1038/srep33315

Stoffels P, Müller MJ, Stachurski S, Terfrüchte M, Schröder S, Ihling N, Wierckx N, Feldbrügge M, Schipper K, Büchs J. 2020. Complementing the intrinsic repertoire of Ustilago maydis for degradation of the pectin backbone polygalacturonic acid. Journal of Biotechnology 307:148163 DOI: doi.org/10.1016/j.jbiotec.2019.10.022

Suhas, Gupta VK, Carrott PJM, Singh R, Chaudhary M, Kushwaha S. 2016. Cellulose: A review as natural, modified and activated carbon adsorbent. Bioresource Technology 216:1066-1076 DOI: doi.org/10.1016/j.biortech.2016.05.106 
790

791

792

793

794

795

796

797

798

799

800

801

802

803

804

805

806

807

808

809

810

811

812

813

814

815

816

817

818

819

820

821

822

823

824

825

826

827

828

829

830

831

832

833

Tamboli AS, Waghmare PR, Khandare RV, Govindwar SP. 2017. Comparative analyses of enzymatic activity, structural study and docking of fungal cellulases. Gene Reports 9:54-60 DOI: doi.org/10.1016/j.genrep.2017.08.008

Textor LC, Colussi F, Silveira RL, Serpa V, Mello BL, Muniz JR, Squina FM, Pereira N, Skaf MS, Polikarpov I. 2013. Joint X-ray crystallographic and molecular dynamics study of cellobiohydrolase I from Trichoderma harzianum: Deciphering the structural features of cellobiohydrolase catalytic activity. The FEBS Journal 280:56-69 DOI: doi.org/10.1111/febs.12049

Teymouri F, Laureano-Perez L, Alizadeh H, Dale BE. 2005. Optimization of the ammonia fiber explosion (AFEX) treatment parameters for enzymatic hydrolysis of corn stover. Bioresource Technology 96:2014-2018 DOI: doi.org/10.1016/j.biortech.2005.01.016

Tribot A, Amer G, Alio MA, de Baynast H, Delattre C, Pons A, Mathias JD, Callois JM, Vial C, Michaud P, Dussap CG. 2019. Wood-lignin: Supply, extraction processes and use as bio-based material. European Polymer Journal 112:228-240 DOI:

doi.org/10.1016/j.eurpolymj.2019.01.007

Vaidya AA, Gaugler M, Smith DA. 2016. Green route to modification of wood waste, cellulose and hemicellulose using reactive extrusion. Carbohydrate Polymers 136:1238-1250 DOI:

doi.org/10.1016/j.carbpol.2015.10.033

Van Walsum GP, Allen SG, Spencer MJ, Laser MS, Antal MJ, Lynd LR. 1996. Conversion of Lignocellulosics Pretreated with Liquid Hot Water to Ethanol. In: Wyman CE, Davison BH, ed. Seventeenth Symposium on Biotechnology for Fuels and Chemicals. Totowa: Humana Press, 157-170.

Verardi A, Lopresto CG, Blasi A, Chakraborty S, Calabrò V. 2020. Chapter 3 - Bioconversion of lignocellulosic biomass to bioethanol and biobutanol. In: Editor(s): Yousuf A, Pirozzi D, Sannino F, eds. Lignocellulosic Biomass to Liquid Biofuels. Cambridge, MA: Academic Press, 67-125.

de Vries R.P., Patyshakuliyeva A., Garrigues S., Agarwal-Jans S. (2020) The Current Biotechnological Status and Potential of Plant and Algal Biomass Degrading/Modifying Enzymes from Ascomycete Fungi. In: Nevalainen H. (eds) Grand Challenges in Fungal Biotechnology. Grand Challenges in Biology and Biotechnology pp 81-120. Springer, Cham. DOI: doi.org/10.1007/978-3-030-29541-7 4

Wakai S., Nakashima N., Ogino C., Tsutsumi H., Hata Y., Kondo A. (2019). Modified expression of multi-cellulases in a filamentous fungus Aspergillus oryzae. Bioresource Technology 276: 146-153. DOI: doi.org/10.1016/j.biortech.2018.12.117

Wang C, Yang J, Wen J, Bian J, Li M, Peng F, Sun R. 2020. Structure and distribution changes of Eucalyptus hemicelluloses during hydrothermal and alkaline pretreatments. International Journal of Biological Macromolecules 133:514-521 DOI:

doi.org/10.1016/j.ijbiomac.2019.04.127

Wang G, Liu X, Zhang J, Sui W, Jang J, Si C. 2018. One-pot lignin depolymerization and activation by solid acid catalytic phenolation for lightweight phenolic foam preparation. Industrial Crops and Products 124:216-225 DOI: doi.org/10.1016/j.indcrop.2018.07.080 Wang W, Feng Y, Chen W, Wang Y, Wilder G, Liu D, Yin Y. 2020. Ultrasonic modification of pectin for enhanced 2-furfurylthiol encapsulation: process optimization and mechanisms. Journal of the Science of Food and Agriculture 100:110-118 DOI: doi.org/10.1002/jsfa.10000

Peer] reviewing PDF | (2020:02:46036:1:0:NEW 4 Jun 2020) 
834 Wang Z, Xu B, Luo H, Meng K, Wang Y, Liu M, Bai Y, Yao B, Tu T. 2020. Production pectin 835 oligosaccharides using Humicola insolens Y1-derived unusual pectate lyase. Journal of

836 Bioscience and Bioengineering 129:16-22 DOI: doi.org/10.1016/j.jbiosc.2019.07.005

837 Whitehead TA, Bandi CK, Berger M, Park J, Chundawat SPS. 2017. Negatively supercharging 838 cellulases render them lignin-resistant. ACS Sustainable Chemistry and Engineering 5:6247-

8396252 DOI: doi.org/10.1021/acssuschemeng.7b01202

840 Wierzbicki MP, Maloney V, Mizrachi E, Myburg AA. 2019. Xylan in the middle: Understanding 841 xylan biosynthesis and its metabolic dependencies toward improving wood fiber for industrial 842 processing. Frontiers in Plant Science 10:176 DOI: doi.org/10.3389/fpls.2019.00176

843 Wohlert J, Berglund LA. 2011. A coarse-grained model for molecular dynamics simulations of 844 native cellulose. Journal of Chemical Theory and Computation 7:753-760 DOI:

845 doi.org/10.1021/ct100489z

846

847

848

849

850

851

852

853

854

855

856

857

858

859

860

861

862

863

864

865

866

867

868

869

870

871

872

873

Wu J, Chandra R, Saddler J. 2019. Alkali-oxygen treatment prior to the mechanical pulping of hardwood enhances enzymatic hydrolysis and carbohydrate recovery through selective lignin modification. Sustainable Energy and Fuels 3:227-236 DOI: doi.org/10.1039/C8SE00452H

Yuan Y, Teng Q, Lee C, Zhong R, Ye Z. 2014. Modification of the degree of 4-O-methylation of secondary wall glucuronoxylan. Plant Science 219-220:42-50 DOI: doi.org/10.1016/j.plantsci.2014.01.005

Ying W, Shi Z, Yang H, Xu G, Zheng Z, Yang J. 2018. Effect of alkaline lignin modification on cellulase-lignin interactions and enzymatic saccharification yield. Biotechnology for Biofuels 11:214 DOI: doi.org/10.1186/s13068-018-1217-6

Zang L, Qiao X, Hu L, Yang C, Liu Q, Wei C, Qiu J, Mo H, Song G, Yang J, Liu C. 2018. Preparation and evaluation of coal fly ash/chitosan composites as magnetic supports for highly efficient cellulase immobilization and cellulose bioconversion. Polymers 10:523 DOI: doi.org/10.3390/polym 10050523

Zeng Y, Zhao S, Yang S, Ding S. 2014. Lignin plays a negative role in the biochemical process for producing lignocellulosic biofuels. Current Opinion in Biotechnology 27:38-45 DOI: doi.org/10.1016/j.copbio.2013.09.008

Zhang X, Wang F, Keer LM. 2015. Influence of surface modification on the microstructure and thermo-mechanical properties of bamboo fibers. Materials 8:6597-6608 DOI: doi.org/10.3390/ma8105327

Zhao J, Chen X, Jia D, Yao K. 2020. Identification of fungal enzymes involving 3phenoxybenzoic acid degradation by using enzymes inhibitors and inducers. Methods $X$ 7:100772 DOI: doi.org/10.1016/j.mex.2019.100772 